\title{
Commentary: Functional or secondary mitral valve regurgitation: Pathoanatomy versus etiology ... changing paradigms and treatment strategies
}

\author{
Kevin D. Accola, MD
}

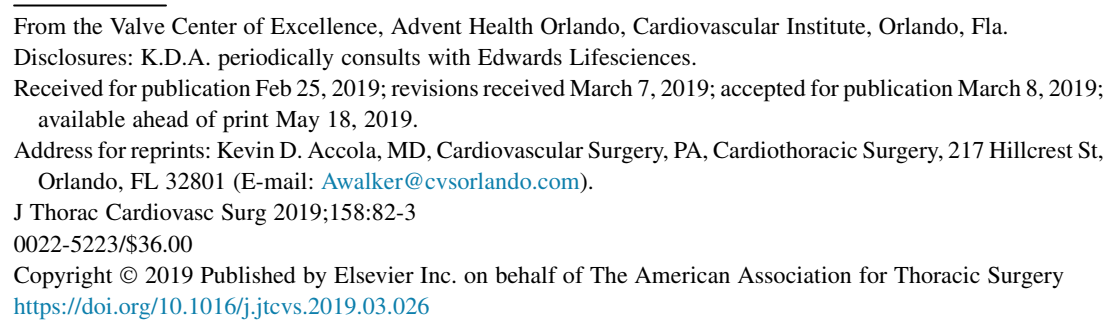

Badhwar and co-authors ${ }^{1}$ are to be congratulated because they have initiated a timely and necessary suggestion for anatomically defining functional mitral valve regurgitation (FMR) or secondary mitral valve regurgitation as defined in the 2017 American College of Cardiology guidelines by Nishimura and colleagues, ${ }^{2}$ published in the Journal of American College of Cardiology. Certainly, ischemic FMR is different from cardiomyopathic FMR and must be approached with a mind-set and paradigm relative to an anatomic perspective. We are treating "ventricular" or "atrial" pathology with an attempted valvular fix. Throw into this fray of treatment strategies the conceptual dilemma of "reactive" FMR, those patients with moderate mitral regurgitation while at rest (or under general anesthesia) but progression of severe mitral regurgitation when the ventricle is under any stress with activity.

Both the recently published articles by Acker and colleagues ${ }^{3}$ and Goldstein and colleagues ${ }^{4}$ clearly demonstrate the poor results at 1-year and 2-year intervals when annular remodeling was compared with mitral valve replacement, with approximately one third of valve annulus remodeling at 1 year and two thirds at 2 years having significant recurrence of mitral regurgitation. I believe the depth of leaflet coaptation relative to the annular plane and ventricular pathoanatomy, irrespective of etiology as suggested by Badhwar and colleagues, ${ }^{1}$ should be the deciding factor whether the valve annulus is remodeled or replaced, or another intervention such as percutaneous technology is used. When small annuloplasty rings are placed, high gradients do occur, particularly with activity. Although we are in the "square wheel" phase of development in new percutaneous advancements, this will certainly continue to evolve and become a variable in our treatment strategies. With the advent of valve-in-valve technologies, this will also have an impact on the decision of surgical strategies in patients in whom the mitral valve is replaced.

Annuloplasty remodeling will yet have a role in these patients if the leaflets are mobile, compliant, and coapting at

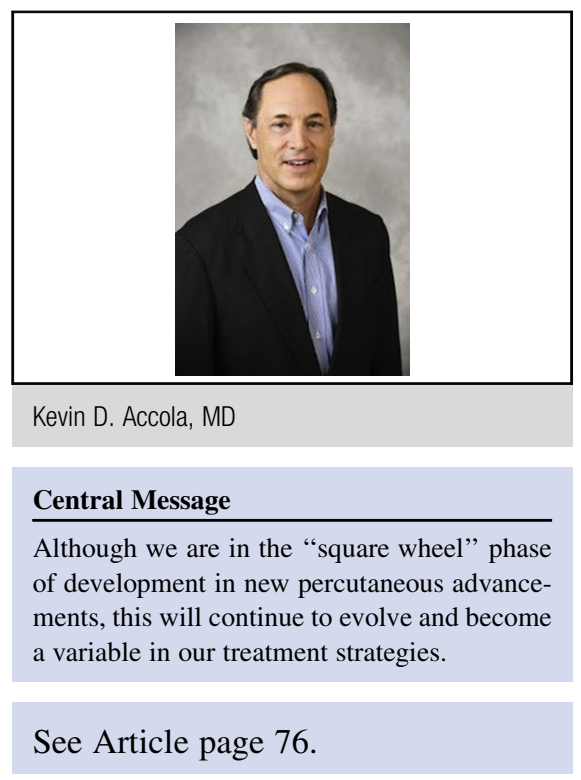

the annular plane echographically. This description by Alan Carpentier is type I valvular pathology, which we all adopted and conversed with from the "beginning of time" relative to mitral valve treatment strategies. Certainly, there are variations of this pathologic process that may be best served with a mitral valve replacement as opposed to an attempted correction with annular remodeling. Functional or secondary mitral regurgitation has become better clarified, and now is the time for a common, more detailed nomenclature. Surgically, we can all make a valve "not leak." But as noted, current clinical data demonstrate early recurrent mitral regurgitation with little to no benefit to the patient as the ventricular process progresses. Perhaps this addition to the literature provides understanding and clarification of FMR anatomic variations, and there will be clinical trials conducted to define treatment strategies best used for each of these. The ultimate goal will be to develop a common nomenclature and subsequent treatment strategies for optional long-term results and patient benefit.

\section{References}

1. Badhwar V, Alkhouli M, Mack MJ, Thourani VH, Ailawadi G. A pathoanatomic approach to secondary functional mitral regurgitation: evaluating the evidence. $J$ Thorac Cardiovasc Surg. 2019;158:76-81.

2. Nishimura RA, Otto CM, Bonow RO, Carabello BA, Erwin JP III, Fleisher LA, et al. 2017 AHA/ACC focused update of the 2014 AHA/ACC guideline for the management of patients with valvular heart disease. J Am Coll Cardiol. 2017; 70:252-89. 
3. Acker MA, Parides MK, Perrault LP, Moskowitz AJ, Gelijns AC, Voisine P, et al. Mitral-valve repair versus replacement for severe ischemic mitral regurgitation. $N$ Engl J Med. 2014;370:23-32.
4. Goldstein D, Moskowitz AJ, Gelijns AC, Ailawadi G, Parides MK, Perrault LP et al. Two-year outcomes of surgical treatment of severe ischemic mitral regurgitation. N Engl J Med. 2016;374:344-53. 